\title{
CONDITIONED MEDIA OF MESENCHYMAL STEM CELLS RECOVERS PLACENTAL GROWTH FACTOR IN PRISTANE MICE MODEL
}

\section{MUHAMMAD ADRIANES BACHNAS ${ }^{1,2 *}$, AMBAR MUDIGD0 ${ }^{1,3}$, BAMBANG PURWANT0 $^{1,4}$, SRI SULISTYOWATI $^{2}$}

${ }^{1}$ Doctorate Program in Medical Sciences, Universitas Sebelas Maret, Solo, Indonesia. ${ }^{2}$ Department of Obstetrics and Gynecology, Division of Maternal-Fetal Medicine, Faculty of Medicine, Universitas Sebelas Maret, Dr. Moewardi Hospital, Solo, Indonesia. ${ }^{3}$ Department of Pathology, Anatomy, Faculty of Medicine, Universitas Sebelas Maret, Dr. Moewardi Hospital, Solo, Indonesia. ${ }^{4}$ Department of Internal Medicine, Faculty of Medicine, Universitas Sebelas Maret, Dr. Moewardi Hospital, Solo, Indonesia. Email: bachnasadri@yahoo.com

Received: 02 August 2019, Revised and Accepted: 04 September 2019

\section{ABSTRACT}

Objectives: A low level of placental growth factor (PlGF) expression in placenta is strongly correlated with pregnancy loss, prematurity, fetal growth restriction, and preeclampsia. Pristane-induced lupus in mice model has been widely used to present placental damage and poor pregnancy outcomes. Conditioned media (CM), which is medium for culturing mesenchymal stem cells (MSCs), have grown much attention recently. It has rich amount of growth factors, exosomes, microvesicles, and immunomodulatory molecules. These could become beneficial resources to recover poor placentation.

Methods: CM taken from the $3^{\text {rd }}$ to $4^{\text {th }}$ passage of the culture were underdone by using explant method of human umbilical cord (hUC). Ninety BALB/c mice were randomly distributed into three groups: Normal, pristane, and pristane + CM group. Mice in normal group were injected with 0.5 ml normal saline and other groups with $0.5 \mathrm{ml}$ pristane. Four weeks later, mice were mated and only pristane $+\mathrm{CM}$ group received therapy of CM-MSCs $0.5 \mathrm{ml}$ single dose after pregnancy was confirmed. On day 16, pregnancy was terminated and the placenta was analyzed for PlGF expression using immunoreactive score and statistically tested with analysis of variance.

Results: The average of PlGF expression in normal, pristane, and pristane + CM group was 9.528, 3.428, and 10.085, respectively. CM have significantly increase PIGF $\left(\mathrm{p}<0.01^{* *}\right)$ and equal to normal $(\mathrm{p}=0.301)$.

Conclusion: CM of hUC-MSCs has shown its therapeutical effect among the low level of PlGF in damaged placenta, and potentially would prevent fetal growth restriction and preeclampsia arose from spiral artery remodeling failure.

Keywords: Conditioned media, Mesenchymal stem cells, Placental growth factor.

(c) 2019 The Authors. Published by Innovare Academic Sciences Pvt Ltd. This is an open access article under the CC BY license (http://creativecommons. org/licenses/by/4. 0/) DOI: http://dx.doi.org/10.22159/ajpcr.2019.v12i10.35198

\section{INTRODUCTION}

Placental growth factor (PIGF) is believed as the most important molecules in placenta that supporting proper angiogenesis and good placentation process [1]. A low level of PIGF will significantly increase the risk of poor pregnancy and provide information to identify highrisk pregnancy before clinical manifestation arise. Some interventions could be done after, but none has given proper results [2].

Pristane induction in mice model has positively correlated with adverse fetal outcomes, especially fetal growth restriction and fetal demise [3]. However, PIGF expression in placenta after pristane induction has never been reported in any study before. Stem cells have become a trending topic as a new modality in therapy. It has been used in many relevant clinical setting. Yet, its usage in the field of obstetrics is lacking [4]. Conditioned media (CM) of human umbilical cord mesenchymal stem cells (hUC-MSCs) have a rich source of many potential growth factors, including vascular endothelial growth factor (VEGF) that has high potentiality on angiogenesis; hepatocyte growth factor and tumor growth factor- $\beta$ that have ability in promoting cell regeneration and suppressing inflammation [5]. In this study, CM of hUC-MSCs is expected to restore poor placentation process in low PIGF expression setting by increasing PIGF expression in placenta.

METHODS

\section{Animals}

We undertake the study at the Faculty of Veterinary Medicine, Universitas Airlangga, Surabaya. The study was approved by the Ethical
Committee of Universitas Airlangga, Surabaya and Universitas Sebelas Maret, Solo and met the criteria of ARRIVE [6] and PREPARE [7] guidelines. BALB/c mice in healthy condition, weighing 25-20 g, were chosen. Standard conditions are used for breeding and maintaining the study.

\section{CM of hUC-MSCs}

CM used in this study were taken from the culture media of hUC-MSCs at the third and fourth passages. We used Dulbecco's Modified Eagle Medium-high glucose supplemented with 5\% human platelet lysate and L-glutamine. After $80 \%$ of confluency had achieved, stem cells were harvested. TrypLE Express was used for harvesting purposes. For the first collection, hUC-MSCs were identified with the standard surface markers (CD 90, CD 105, and CD 73) using flow cytometry. Explant method with multiple harvesting method was used for culturing process in normoxic condition [8,9]. After isolation of the hUC, vessels were dissected. Umbilical tissue then chopped into tiny pieces and placed in the culture dish $\left( \pm 2 \mathrm{~mm}^{2}\right.$ area) and put into CM for multiple passages. Antibiotics and antimycotic were also added as standard for eliminating contamination possibility.

Damaged placenta model using pristane and treatment using CM Ninety mice were put into three groups by randomization: (I) Normal, (II) pristane, and (III) pristane + CM. Mice in Group I were injected with $0.5 \mathrm{ml}$ of normal saline, intraperitoneally; meanwhile, Group II and III were injected with $0.5 \mathrm{ml}$ pristane (2,6,10,14-tetramethylpentadecane). It takes 4 weeks to develop immunological reaction induced by pristane that could potentially damage placenta as the pregnancy happen. After 4 weeks, mice were mated. Synchronization was done using five IU 
pregnant more serum gonadotropin and followed by human chorionic gonadotropin 2 days later. The breeding procedure was proceeded with monomating using 7-month-old male mice. As the pregnancy was confirmed by copulatory plug appearance, Group III received intraperitoneal injection of $0.5 \mathrm{ml} \mathrm{CM}$ and others received normal saline.

\section{Data collection and statistical analysis}

Day 16 was chosen as the termination period as it represents full-term pregnancy. Placenta was collected and measured for PIGF expression using immunohisthochemistry. Measurement was done with immunoreactive score of Remmele. Statistical analysis was performed using one-way analysis of variance (ANOVA), after the normality test showed normal distribution. Least significant difference (LSD) post hoc test was performed following ANOVA and showed significant results $(\mathrm{p}<0.05)$. Statistical analyses were performed with SPSS version 22.0 for Mac OS (IBM Corp. Released 2013, Armonk, NY).

\section{RESULTS}

CM of hUC-MSCs were produced in the amount of $360 \mathrm{ml}$ from a single culture process, taken from the $3^{\text {rd }}$ and $4^{\text {th }}$ passages. For the assurance, hUC-MSCs were checked for its confluent and harvested at above $80 \%$. Total passage cell number of hUC-MSCs was $119,500,000$ cells and passage concentration was $41,564 \mathrm{cell} / \mathrm{ml}$. In this study, pristane provision has significantly caused a detrimental effect on placenta showed by a dramatic decrease of PIGF expression in the placenta (from 9.528 in the normal group to 3.428 in the pristane group, $\mathrm{p}<0.01$ ). CM from hUC-MSCs that were proposed as therapy in this study, have answered the expectation since as it showed impact on significant increase of PIGF expression in pristane + CM group $(10.085, \mathrm{p}<0.01)$. This increase is sufficient enough to equal normal level $(p=0.301)$ as seen in Fig. 1.

\section{DISCUSSION}

In this study, CM of hUC-MSCs had significantly increased PIGF expression on the damaged placenta to the normal level. This effect could potentially provide excellent placental vascular remodeling and further prevent fetal growth restriction and preeclampsia [10].

Oxidative stress causes decreasing production of PIGF from syncytiotrophoblast (STB) [10]. Pristane has been used widely to induce lupus in mice models $[11,12]$. This model represents a chronic inflammatory state that best suited to cause oxidative stress resulting in placental damage and was expected to decrease placental PIGF expression [13]. Pristane administration intraperitoneally causes interferon (IFN)-I dysregulation by disturbing IFNAR signaling

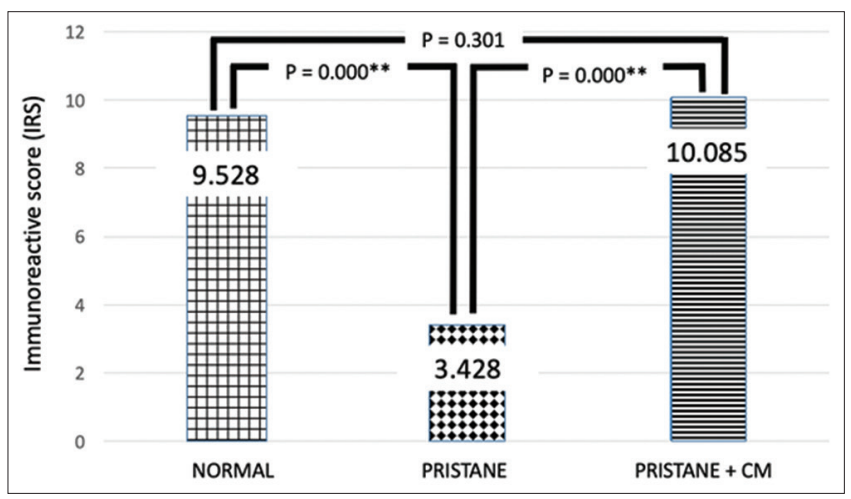

Fig. 1: Placental growth factor placental expression. Comparison of the average PIGF placental expression in all groups: Normal, pristine, and pristane + CM treatment. Data are presented as the mean \pm standard deviation in each group and analyzed by ANOVA followed by LSD post hoc tests ( $* *$ is considered significant, $\mathbf{p}<0.01$ ) fashion $[11,12]$. It makes peritoneum cells become severely irritated and necrotic [13]. The sudden massive production of necrotic cells leads to massive nucleosomes production. As the natural immune systems could not coupe promptly with the massive nucleosomes, a lousy clearance happens and this leads to the maturation of B-cells [14]. B-cells then produces autoantibody with the specific Fc receptors representing a specific pattern of those DNA fragments and later on recognize self-DNA as an antigen [14].

Pristane also induces the natural response of lymphoid tissue and adipose tissue to present a cancerous formation called lipogranulomas [11,12]. Immature monocytes produce IFN-1 and being mediated exclusively by TLR-7-MyD88 pathway [12,14]. Endogenous TLR7 ligands such as U1RNA has been proven involve in this pathological process $[12,14]$. Autobody production then is concentrated in ectopic lymphoid tissue since the uptake of immune complex through Fc receptors is dispensable $[12,14]$. This ectopic lymphoid tissue becomes host for T-cells and B-cells interaction via specific toll-like receptors (TLR) ligand. This interaction would further develop into B-cells maturation and produce auto-antibody correlated with broad manifestation of autoimmune diseases such as lupus, Sjogren, rheumatoid arthritis, and others [15]. Moreover, as the autoimmunity developed, the production of proinflammatory agents such as interleukin (IL)-1, IL-6, IL-12, and tumor necrosis factor- $\alpha$ is also increasing. As the pregnancy rolling with its placentation, this inflammatory state produced by autoimmune process is expected to abrogate the production of angiogenic factors resulting on placental damage and vascular remodeling failure $[10,16]$. The main angiogenic factor in the placenta is PIGF. This study has given proof that pristane administration had significantly caused low PIGF expression.

CM of hUC-MSCs have shown its ability in modulating the immune system in previous studies [4]. Extracellular vesicles (EVs) of CM can react as an immunosuppressant and suppressing the release of cytokine and other inflammatory agents [17]. EV is protein and lipids carrier that works importantly in cellular processes [17]. This molecule can inhibit autoreactive lymphocyte proliferation and promote anti-inflammatory cytokines production [17]. Fas receptors, which play an essential part in antibody formation, could be desensitized by EC [17]. Furthermore, the balance between T helper (Th1) and Th2 is created [18]. EVs also influence Th17 suppression and Treg production [4,17]. By this capability, CM of hUC-MSCs are expected to be agile in canceling the vascular remodeling failure and promoting placental cells regeneration.

CM could function as anti-aggregator through the activation of prosurvival signaling cascades (AKT, Erk1/2, CREB, and c-Jun) [19]. CM are expected to trigger lipoxin, as one of the crucial molecules for good vascular remodeling has been shown by aspirin that triggered aspirintriggered lipoxin A4. This is why we used normoxia instead of hypoxia conditioned to provide a better natural composure [20]. We used the explant method with multiple harvest technic to provide more viable cells in a shorter culturing process $[8,9]$. We chose the hUC for the source of the stem cells because it is originally unused material after birth $[8,9]$. We used serum-free media to elude allergic reactions $[8,9]$.

Some studies have shown that VEGF recombinant injection is one of the promising therapy for preeclampsia in the future, but recently some considerations have retracted it from the further translational study [21]. Instead of its interaction with the VEGF receptor (VEGFr), VEGF recombinant also binds with high affinity to fetal liver kinase 1 receptor (Flk-1) and therefore, may lead to side effects related to excess Flk-1 signaling and causing many side effects such as edema and organ failure [22]. Different from VEGF recombinant injection, natural VEGF which is produced in MSCs culture and also PIGF is shown selectively attach to VEGFr, causing beneficial effect and no side effect [23]. In various studies, PIGF also has been proven its potency to prevent the effects of placental ischemia by increasing uteroplacental perfusion. PIGF is also able to reduce circulating sFlt- 1 and oxidative stress [24]. This study showed how placenta, especially STB, reacts 
after CM provision. The results have shown that CM of hUC-MSCs have effectively sensitized STB to produce a large amount of PIGF as seen in immunohistochemistry result of PlGF expression on STB. These results have given evidence to support the usage of CM of hUC-MSCs as a new therapy approach for fetal growth restriction and preeclampsia.

In comparison to stem-cells itself, $\mathrm{CM}$ are more suitable to be used in pregnancy. Different from the stem cells, CM are costless, easy to handle, and easy to store $[4,5]$. CM do not need the homing process and do not stimulate immune rejection from the human body $[4,25]$. CM also do not have safety issues regarding tumorigenicity, carcinogenesis, and organogenesis $[4,26]$

\section{CONCLUSION}

This study has proven that CM of hUC-MSCs recover low placental PIGF expression in damaged placenta to the normal condition and are expected to be used as novel therapy for preventing fetal growth restriction and preeclampsia in the near future.

\section{ACKNOWLEDGMENT}

The authors would like to expresses the gratitude to Professor Widjiati, Faculty of Veterinary Medicine, Universitas Airlangga and Dr. Cynthia Retna Sartika, ProSTEM, for providing necessary support in due course of the work

\section{AUTHORS' CONTRIBUTIONS}

All authors contributed equally in the design, development, review, and finalization of the paper.

\section{CONFLICTS OF INTEREST}

The authors declare that they have no conflicts of interest.

\section{REFERENCES}

1. Kim MY, Buyon JP, Guerra MM, Rana S, Zhang D, Laskin CA, et al. Angiogenic factor imbalance early in pregnancy predicts adverse outcomes in patients with lupus and antiphospholipid antibodies: Results of the PROMISSE study. Am J Obstet Gynecol 2016;214:108.

2. Selvaraj LR, Rose N, Ramachandran M. First trimester screening for pre-eclampsia and fetal growth restriction. J Fetal Med 2016;3:77-84.

3. Chaiworapongsa T, Romero R, Korzeniewski SJ, Kusanovic JP, Soto E, Lam J, et al. Maternal plasma concentrations of angiogenic/ antiangiogenic factors in the third trimester of pregnancy to identify the patient at risk for stillbirth at or near term and severe late preeclampsia. Am J Obstet Gynecol 2013;208:287.e1-.87E+17.

4. Vizoso FJ, Eiro N, Cid S, Schneider J, Perez-Fernandez R. Mesenchymal stem cell secretome: Toward cell-free therapeutic strategies in regenerative medicine. Int J Mol Sci 2017;18:1852.

5. Ferreira JR, Teixeira GQ, Santos SG, Barbosa MA, Almeida-Porada G, Gonçalves RM, et al. Mesenchymal stromal cell secretome: Influencing therapeutic potential by cellular pre-conditioning. Front Immunol 2018;9:2837.

6. Kilkenny C, Browne WJ, Cuthill IC, Emerson M, Altman DG. Improving bioscience research reporting: The arrive guidelines for reporting animal research. Animals 2013;4:35-44.

7. Smith AJ, Clutton RE, Lilley E, Hansen KEA, Brattelid T. PREPARE:
Guidelines for planning animal research and testing. Lab Anim 2018;52:135-41.

8. Pawitan J, Liem I, Budiyanti E. Umbilical cord derived stem cell culture: Multiple-harvest explant method. Int J PharmTech Res 2014;6:1202-8.

9. Pawitan J, Kispa T, Mediana D, Goei N, Fasha I, Liem I, et al. Simple production method of umbilical cord derived mesenchymal stem cell using xeno-free materials for translational research. J Chem Pharm Res 2015;7:652-6

10. Redman CW, Staff AC. Preeclampsia, biomarkers, syncytiotrophoblast stress, and placental capacity. Am J Obstet Gynecol 2015;213:S9.e1, S9-11.

11. Kuroda Y, Akaogi J, Nacionales DC, Wasdo SC, Szabo NJ, Reeves WH, et al. Distinctive patterns of autoimmune response induced by different types of mineral oil. Toxicol Sci 2004;78:222-8.

12. Reeves WH, Lee PY, Weinstein JS, Satoh M, Lu L. Induction of autoimmunity by pristane and other naturally occurring hydrocarbons. Trends Immunol 2009;30:455-64

13. Calvani N, Caricchio R, Tucci M, Sobel ES, Silvestris F, Tartaglia P, et al. Induction of apoptosis by the hydrocarbon oil pristane: Implications for pristane-induced lupus. J Immunol 2005;175:4777-82.

14. Satoh M, Reeves WH. Induction of lupus-associated autoantibodies in BALB/c mice by intraperitoneal injection of pristane. J Exp Med 1994;180:2341-6.

15. Clynes R, Calvani N, Croker BP, Richards HB. Modulation of the immune response in pristane-induced lupus by expression of activation and inhibitory fc receptors. Clin Exp Immunol 2005;141:230-7.

16. Cetin I, Mazzocco MI, Giardini V, Cardellicchio M, Calabrese S, Algeri $\mathrm{P}$, et al. $\mathrm{PlGF}$ in a clinical setting of pregnancies at risk of preeclampsia and/or intrauterine growth restriction. J Matern Fetal Neonatal Med 2017;30:144-9.

17. Bruno S, Deregibus MC, Camussi G. The secretome of mesenchymal stromal cells: Role of extracellular vesicles in immunomodulation. Immunol Lett 2015;168:154-8.

18. Gao F, Chiu SM, Motan DA, Zhang Z, Chen L, Ji HL, et al. Mesenchymal stem cells and immunomodulation: Current status and future prospects. Cell Death Dis 2016;7:e2062.

19. Legaki E, Roubelakis MG, Theodoropoulos GE, Lazaris A, Kollia A, Karamanolis G, et al. Therapeutic potential of secreted molecules derived from human amniotic fluid mesenchymal stem/Stroma cells in a mice model of colitis. Stem Cell Rev Rep 2016;12:604-12.

20. Teixeira FG, Panchalingam KM, Anjo SI, Manadas B, Pereira R, Sousa $\mathrm{N}$, et al. Do hypoxia/normoxia culturing conditions change the neuroregulatory profile of wharton jelly mesenchymal stem cell secretome? Stem Cell Res Ther 2015;6:133

21. Phipps EA, Thadhani R, Benzing T, Karumanchi SA. Pre-eclampsia: Pathogenesis, novel diagnostics and therapies. Nat Rev Nephrol 2019;15:275-89.

22. Chau K, Hennessy A, Makris A. Placental growth factor and preeclampsia. J Hum Hypertens 2017;31:782-6.

23. Fisher SJ. Why is placentation abnormal in preeclampsia? Am J Obstet Gynecol 2015;213:S115-22.

24. Lu L, Kingdom J, Burton GJ, Cindrova-Davies T. Placental stem villus arterial remodeling associated with reduced hydrogen sulfide synthesis contributes to human fetal growth restriction. Am J Pathol 2017; 187:908-20.

25. Boomsma RA, Geenen DL. Mesenchymal stem cells secrete multiple cytokines that promote angiogenesis and have contrasting effects on chemotaxis and apoptosis. PLoS One 2012;7:e35685.

26. Konala VB, Mamidi MK, Bhonde R, Das AK, Pochampally R, Pal R, et al. The current landscape of the mesenchymal stromal cell secretome: A new paradigm for cell-free regeneration. Cytotherapy 2016;18:13-24. 